\title{
Changes in bronchial inflammation during acute exacerbations of chronic bronchitis
}

\author{
S. Gompertz, C. O'Brien, D.L. Bayley, S.L. Hill, R.A. Stockley
}

\begin{abstract}
Changes in bronchial inflammation during acute exacerbations of chronic bronchitis. S. Gompertz, C. O'Brien, D.L. Bayley, S.L. Hill, R.A. Stockley. (C)ERS Journals Ltd 2001.

ABSTRACT: There are little data describing noncellular changes in bronchial inflammation during exacerbations of chronic bronchitis. The relationship between sputum colour and airway inflammation at presentation has been assessed during an exacerbation in patients with chronic bronchitis and a primary care diagnosis of chronic obstructive pulmonary disease.

Sputum myeloperoxidase, neutrophil elastase, leukotriene $\mathbf{B}_{\mathbf{4}}\left(\mathbf{L T B}_{4}\right)$, interleukin-8 (IL-8), sol:serum albumin ratio and serum C-reactive protein were measured in patients presenting with an exacerbation and mucoid $(n=27)$ or purulent sputum $(n=42)$.

Mucoid exacerbations were associated with little bronchial or systemic inflammation at presentation, and sputum bacteriology was similar to that obtained in the stable state. Purulent exacerbations were associated with marked bronchial and systemic inflammation ( $p<0.025$ for all features) and positive sputum cultures $(90 \%)$. Resolution was related to a significant reduction in $\operatorname{LTB}_{4}(p<0.01)$, but no change in IL-8, suggesting that $\mathbf{L T B}_{4}$ may be more important in neutrophil recruitment in these mild, purulent exacerbations. In the stable state, IL-8 remained higher in patients who had experienced a purulent exacerbation $(2 p<0.02)$.

The presented results indicate that exacerbations of chronic bronchitis, defined by sputum colour, differ in the degree of bronchial and systemic inflammation. Purulent exacerbations are related to bacterial infection, and are associated with increased neutrophilic inflammation and increased leukotriene $\mathbf{B}_{\mathbf{4}}$ concentrations.

Eur Respir J 2001; 17: 1112-1119.
\end{abstract}

Dept of Respiratory Medicine, Queen Elizabeth Hospital, Birmingham, UK.

Correspondence: S. Gompertz Dept of Respiratory Medicine First Floor, Nuffield House

Q. E. Hospital

Edgbaston

Birmingham B15 2TH

UK

Keywords: Bronchitis

chronic bronchitis

exacerbations

inflammation

Received: December 311999

Accepted after revision January 82001

This work was supported by an unrestricted educational grant from GlaxoSmithKline.
Exacerbations of chronic bronchitis and chronic obstructive pulmonary disease (COPD) are related to increased morbidity and mortality, and are usually defined on clinical grounds as a worsening of respiratory symptoms $[1,2]$. The nature of these exacerbations is loosely defined and some may reflect an increase in airflow obstruction, whilst others (which may be related to bacterial infection) are associated with an influx of neutrophils [3-5], sputum purulence and increased neutrophil elastase activity [6]. The loose definition and heterogeneous aetiology of exacerbations may explain studies which show that the use of steroids [7], antibiotics [2] and placebo [2] are all associated with resolution of symptoms. In addition, the characterization of exacerbations in studies of patients with lung disease is often relatively superficial and depends largely on clinical symptoms and simple physiological measurements. For instance, recent data have shown that a significant proportion of patients $(\sim 30 \%)$, classified as having COPD by their primary care physician (on clinical grounds alone), have radiological evidence of bronchiectasis detectable by high-resolution computed tomography (HRCT) scanning [8]. This heterogeneity adds further difficulties when interpreting published literature. Data relating to bronchial inflammation during exacerbations of chronic bronchitis and/or COPD are confined largely to descriptions of inflammatory cell numbers during an exacerbation, and in the stable clinical state $[3-5$, 9]. The number of patients in these studies is small (generally $<25$ ), and has usually involved the assessment of different patients during the exacerbation and in the stable state $[3-6,9]$.

The purpose of the present study, therefore, was to assess the biochemical nature and resolution of airway inflammation in a large group of patients with smoking-related chronic bronchitis and a primary care diagnosis of COPD, who presented with an acute exacerbation. In particular, the aim was to determine whether the macroscopic nature of the secretions reflected the degree of airway inflammation, and whether this influenced the biochemical resolution of the exacerbation.

\section{Methods}

\section{Subjects}

The present study identified patients aged $40-$ 80 yrs who presented to their primary care physician with an acute exacerbation of chronic bronchitis 
(daily sputum production for at least 3 months of 2 consecutive years), and in whom a diagnosis of COPD had been made on clinical grounds alone. An exacerbation was identified as a combination of worsening respiratory symptoms (including breathlessness, sputum volume, colour or viscosity, cough, wheeze or chest pain), with or without systemic symptoms (malaise; fever; rigors), which caused the patient to seek medical advice. Those who had received recent antibiotic therapy (previous 4 weeks) or where oral corticosteroid therapy or hospital admission were thought to be mandatory were excluded from the study.

The study was approved by the South Birmingham Health Authority Ethics Committee and all subjects provided written informed consent.

\section{Sputum classification}

Patients were seen by a respiratory nurse on the day of presentation (day 1), and a fresh spontaneous sputum sample was obtained. An experienced microbiology technician allocated the sample a number by reference to a standard colour chart (BronkoTest, Heredilab Inc., Salt Lake City, UT, USA) according to its predominant macroscopic appearance. Values of $0-2$ (colourless-white) were classified as mucoid, and 3-8 (ranging from pale yellow to dark green) as increasingly purulent sputum.

Quantitative sputum culture was performed on an aliquot of the initial sample as described previously [10]. The remaining sputum was centrifuged at $50,000 \times g\left(4^{\circ} \mathrm{C}\right)$ for 90 mins and the sputum sol phase was harvested and stored at $-70^{\circ} \mathrm{C}$ until analysed. Ten millilitres of blood was also obtained, allowed to clot, centrifuged at 3,000 revolutions per minute (rpm) for 10 mins and the serum was stored at $-70^{\circ} \mathrm{C}$ until required.

\section{Treatment protocol}

All subjects were treated and followed as outpatients. Patients with mucoid exacerbations had any regular inhaled corticosteroid prescribed prior to study entry stopped; although all other therapies, including beta- 2 agonists and anticholinergic agents, were continued. These subjects then received either fluticasone propionate $(1,000 \mu \mathrm{g}$ per day by metered dose inhaler) or matching placebo for 14 days, in order to determine whether inhaled steroids alter lung inflammation. This dose was chosen as it has been shown to have an anti-inflammatory effect on lung secretions [11], and to reduce the severity of exacerbations in patients with COPD [12].

Individuals with macroscopically purulent sputum (colour numbers $\geqslant 3$ ) received either 10 days of continuous therapy with oral cefuroxime axetil (500 mg twice daily) or 5 days of therapy followed by 5 days of placebo tablets. The antibiotic was chosen because of its known activity against the respiratory pathogens most commonly identified in exacerbations of COPD, namely Streptococcus pneumoniae, nontypeable Haemophilus influenzae and Moraxella catarrhalis [13].

\section{Subsequent visits}

Patients were reviewed by the study team on the fifth day of treatment (day 5), at the end of the treatment period (day 10 for purulent and day 14 for mucoid exacerbations), and 28 and 56 days after presentation, when in the stable clinical state. Further blood and sputum samples (over $4 \mathrm{~h}$ from rising) were obtained on the day of each visit and whenever possible (providing no further exacerbation was present), processed and stored as stated previously. On day 56 (in the stable clinical state), quantitative sputum bacteriology was repeated and dynamic lung volumes were measured using a wedge bellows spirometer (Vitalograph, Buckinghamshire, UK). Short-acting bronchodilators were omitted for $6 \mathrm{~h}$ prior to spirometry and long-acting bronchodilators for $12 \mathrm{~h}$. The best of three satisfactory traces agreeing within $50 \mathrm{~mL}$ for forced expiratory volume in one second (FEV1) and $150 \mathrm{~mL}$ for vital capacity (VC) were accepted for analysis. The measurements were repeated 20 mins after inhalation of $400 \mu \mathrm{g}$ of salbutamol, to determine the presence of any reversibility. HRCT scanning (1 $\mathrm{mm}$ slices) was also performed and reported by an experienced thoracic radiologist, to identify patients with bronchial dilatation. The scans were reviewed some months later (without the initial report) with a senior respiratory physician, to obtain a consensus opinion on the presence of bronchiectasis, using the criteria first described by NAIDICH et al. [14] and recently reviewed by Hansell [15]. Patients with tubular bronchiectasis were excluded from the final analysis, as previous work has suggested that, even when clinically indistinguishable, these patients have more bronchial inflammation [16].

\section{Biochemical analysis}

Myeloperoxidase. Myeloperoxidase (MPO) activity was measured by a chromogenic substrate assay relative to a standard preparation of lysed neutrophils, as described previously [17], and used as a marker of sputum neutrophil content and activation. The results are expressed as arbitrary units $\cdot \mathrm{mL}^{-1}$ of sputum.

Neutrophil elastase. Elastase activity was assessed spectrophotometrically using the synthetic substrate methoxysuccinyl-ala-ala-pro-val-paranitroanilide (MeOSAAPVpNa; Sigma-Aldrich Company Ltd, Poole, Dorset, UK). Twenty $\mu \mathrm{L}$ of standard or sample were added to the wells of a microtitre plate (Life Technologies Ltd, Paisley, UK), followed by MeOSAAPVpNa $(0.3 \mathrm{nM})$ in phosphate buffer $(0.2 \mathrm{M}$, $\mathrm{pH}$ 8.0). The reaction was allowed to continue for $1 \mathrm{~h}$ at $37^{\circ} \mathrm{C}$ and then stopped by the addition of $200 \mu \mathrm{L}$ of $1 \mathrm{~N}$ acetic acid. The absorbence was read at $410 \mathrm{~nm}$ and the activity derived from the standard curve by interpolation. The inter-assay coefficient of variation was 
$<1 \%$, with a lower limit of detection of $0.8 \mathrm{nM}$, and sample results below this level were taken as zero for statistical purposes.

Chemoattractants. Both interleukin-8 (IL-8) and leukotriene $\mathrm{B}_{4}\left(\mathrm{LTB}_{4}\right)$ were measured using commercially available enzyme-linked immunosorbent assay (ELISA) kits ( $\mathrm{R}$ and D Systems Europe Ltd, Abingdon, UK and Amersham International plc, Buckinghamshire, UK, respectively). The characteristics and recovery of these assays has been described previously [17].

Sputum sol and serum albumin. Albumin was measured by radial immunodiffusion using a commercially available kit (The Binding Site Ltd, Birmingham, UK). The inter-assay coefficient of variation was $<5 \%$ $(\mathrm{n}=6)$. Sputum sol:serum ratios (expressed as a percentage) were calculated, providing an assessment of protein "leakage" from the blood into the lung [18].

C-reactive protein. Serum C-reactive protein (CRP) was measured by radial immunodiffusion using a commercially available kit (The Binding Site Ltd, Birmingham, UK) with an inter-assay coefficient of variation of $2.2 \%$. Five $\mu \mathrm{L}$ of standard or sample was added to each well, and the plate was incubated for at least $72 \mathrm{~h}$ at room temperature. Precipitation ring diameters were measured using an eye piece graticule, and a regression curve was constructed of the square of the diameter of the precipitation ring versus concentration of the standards. The concentration of protein in the unknown samples was calculated by interpolation from this standard curve. The lower limit of detection for this assay is $2 \mathrm{mg} \cdot \mathrm{L}^{-1}$, and sample results below this level were taken as zero for statistical purposes.

\section{Statistical analysis}

All statistical analyses were performed using the SPSS statistical package (Version 8.0. Chicago, IL, USA). Age and FEV1 are expressed as mean \pm SD, and the patient groups were compared using the unpaired t-test. The Chi-squared or Fischer's exact test were used to compare categorical data between groups, and changes in sputum bacteriology, colour and free elastase within groups. Inflammatory data are expressed as median (interquartile range), and displayed graphically as box and whisker plots. Changes compared to presentation with the exacerbation were analysed using the Wilcoxon signed-rank test for paired data, and differences between patient groups were compared with the Mann-Whitney U-test. Twotailed tests were used to determine differences between groups when stable, and single-tailed tests were used to determine the differences between the groups at the start of exacerbation, and within groups as the exacerbation resolved. The level of statistical significance was taken as $<0.05$.

\section{Results}

Eighty-four patients presented with an acute exacerbation of their lung disease and provided an adequate sputum sample for analysis at day 1 . Although the definition of an exacerbation was broad, 82 of the 84 patients fulfilled the "goldstandard" criteria for exacerbations first described by ANTHONISEN et al. [2]. Thirty-five had all three major symptoms (increased dyspnoea, sputum purulence and sputum volume), 38 had two major symptoms and nine had one major and one minor symptom (increasing cough or fever). The remaining two patients had changes in sputum viscosity alone, with and without malaise. Since the study was designed to assess the biochemical nature of the episode, they were also included in the data set. HRCT scanning showed evidence of tubular bronchiectasis in 15 patients (who were otherwise clinically indistinguishable) and these were excluded from further analysis. The remaining 69 patients had a clear improvement in their presenting symptoms by the time they were re-studied in the clinically stable state.

Twenty-seven of the patients had mucoid sputum at presentation with the exacerbation (referred to as mucoid bronchitics) and 42 had purulent sputum (referred to as purulent bronchitics). By definition the mucoid bronchitics had colourless or white sputum at presentation (colour number $<3$ ), whereas those with a purulent exacerbation had a higher (median; interquartile range) sputum colour number (4.0; $4.0-5.0 ; \mathrm{p}<0.001)$.

\section{Patient characteristics}

The characteristics of the patients are summarized in table 1 . There were no differences in the proportions of current smokers or of those on inhaled

Table 1.-Patient characteristics

\begin{tabular}{lcc}
\hline & $\begin{array}{c}\text { Mucoid } \\
\text { bronchitics }\end{array}$ & $\begin{array}{c}\text { Purulent } \\
\text { bronchitics }\end{array}$ \\
\hline $\begin{array}{l}\text { Subjects n } \\
\text { Age yrs }\end{array}$ & 27 & 42 \\
Males n & $63.2 \pm 7.5$ & $64.8 \pm 8.9$ \\
$\begin{array}{l}\text { Smokers current (ex) } \\
\text { Stable state pre BD }\end{array}$ & 17 (10) & $18(24)$ \\
$\quad$ FEV1 \% pred & $66.8 \pm 23.2$ & $55.9 \pm 22.0$ \\
$\begin{array}{l}\text { Stable state pre BD } \\
\text { FEV1/VC }\end{array}$ & $53.6 \pm 16.9$ & $50.8 \pm 16.0$ \\
$\begin{array}{l}\text { Increase in FEV1 after } \\
\text { salbutamol L }\end{array}$ & $0.20 \pm 0.12$ & $0.16 \pm 0.14$ \\
$\begin{array}{l}\text { Patients with FEV1/VC } \\
\text { ratio <70\% \% }\end{array}$ & 74.1 & 82.9 \\
$\begin{array}{l}\text { On inhaled steroids } \\
\text { prior to study n (\%) }\end{array}$ & $12(44.4)$ & $22(52.4)$ \\
On oral theophylline n & 2 & 4 \\
\hline
\end{tabular}

Demographic data are presented as mean \pm SD unless otherwise stated; BD: bronchodilator; FEV1: forced expiratory volume in one second; VC: vital capacity. There were no significant differences between the two groups of patients. 
steroids or oral theophyllines prior to the start of the study.

Patients presenting with mucoid sputum had a higher mean prebronchodilator FEV1 in the stable state, than those who had presented with a purulent exacerbation (table 1), however, this failed to achieve statistical significance $(2 p=0.058)$. The majority of patients $(79 \%)$ had airflow obstruction (FEV1/ $\mathrm{VC}<70 \%$ ) and only $31 \%$ of the total had significant reversibility $(>200 \mathrm{~mL}$ and $>15 \%$ increase in FEV1 over baseline) following $\beta_{2}$-agonist.

\section{Sputum microbiology at presentation}

At presentation nine of the mucoid samples (33\%) grew an identifiable pathogen, but the bacterial load was $>10^{7}$ colony forming units $(\mathrm{cfu}) \cdot \mathrm{mL}^{-1}$ in only five (19\% of the total). The organisms cultured from these nine patients included $H$. parainfluenzae [5], nontypeable $H$. influenzae [3] and $N$. meningitidis [1]. Conversely, most of the purulent samples $(90 \%)$ had a positive bacterial culture at presentation and in the majority $(83 \%)$, the bacterial load was $>10^{7} \mathrm{cfu} \cdot \mathrm{mL}^{-1}$ ( $<0.001$ compared with the mucoid group). The organisms included $H$. influenzae [21], S. pneumoniae [7], M. catarrhalis [6] and $H$. parainfluenzae [4].

\section{Inflammatory markers at presentation}

At presentation, the mucoid bronchitics had significantly lower MPO and elastase activity (elastase detectable in only five samples; $19 \%$ ), IL-8, LTB $_{4}$ and protein leakage than the purulent bronchitics (table 2). Notably, elastase activity was detectable in $32(76 \%)$ of the samples from the latter group of patients $(\mathrm{p}<0.0001)$.

\section{Sputum microbiology in the stable state}

When the two groups were restudied in the stable state (day 56), the majority of samples in both groups were macroscopically mucoid. The median (interquartile range) sputum colour for the purulent bronchitics had fallen $(\mathrm{p}<0.001)$ to $2.0(2.0-4.0)$, and was no longer different $(2 p>0.1)$ from the mucoid bronchitics. There was no change in the proportion of samples containing an identifiable pathogen $(33 \%)$, or with bacterial loads $>10^{7} \mathrm{cfu} \cdot \mathrm{mL}^{-1}(25 \%)$ from the mucoid

Table 2. - Inflammatory mediators at presentation

\begin{tabular}{lcc}
\hline & $\begin{array}{c}\text { Mucoid } \\
\text { bronchitics }\end{array}$ & $\begin{array}{c}\text { Purulent } \\
\text { bronchitics }\end{array}$ \\
\hline MPO units·mL $\mathrm{mL}^{-1}$ & $0.48(0.37-0.69)$ & $0.62(0.42-1.50)^{+}$ \\
$\mathrm{NE} \mathrm{nM}$ & $0.0(0.0-0.0)$ & $7.6(0.8-13.8)^{* * *}$ \\
IL-8 nM & $2.4(0.7-4.7)$ & $5.5(2.8-12.6)^{* * *}$ \\
$\mathrm{LTB}_{4} \mathrm{nM}$ & $3.4(1.1-11.3)$ & $7.1(4.6-15.2)^{+}$ \\
Albumin ratio \% & $0.4(0.3-0.9)$ & $1.4(0.7-3.1)^{* * *}$ \\
\hline
\end{tabular}

Data are presented as median (interquartile range). MPO: myeloperoxidase; NE: neutrophil elastase; IL-8: interleukin-8; $\mathrm{LTB}_{4}$ : leukotriene $\mathrm{B}_{4} ;{ }^{+}: \mathrm{p}<0.025 ;{ }^{* * *}: \mathrm{p}<0.001$. bronchitics. However, samples from the purulent bronchitics had fewer $(33 \%)$ positive cultures $(\mathrm{p}<0.0001)$ and only $24 \%(\mathrm{p}<0.0001)$ had a high bacterial load, indicating a major change compared to the start of the exacerbation. In the stable state, the microbiological features of this group were no different from the mucoid bronchitics.

\section{Inflammatory markers in the stable state}

The biochemical data for the mucoid bronchitics was unaltered in the stable state. However, there was a significant decrease in most parameters in the purulent bronchitics, with the exception of IL-8, which remained essentially unaltered (table 3 ). Importantly, there had also been a marked decrease in the number of elastase positive samples $(p<0.0001)$, with activity remaining detectable in only 34\%. Data for the two bronchitic groups in the stable state (day 56) were similar, with the exception of IL-8, which remained higher $(2 \mathrm{p}<0.02)$ in the group that had presented with purulent sputum.

\section{Time course of changes}

The mucoid chronic bronchitics showed little change in inflammation throughout the study, although the MPO concentration did fall from 0.48 (interquartile range; $0.37-0.69)$ to $0.19(0.10-0.51)$ units $\cdot \mathrm{mL}^{-1}$ by the fifth day $(\mathrm{p}<0.005)$. This fall was maintained to the 28th day, and thereafter, MPO rose to pretreatment levels (tables 2 and 3). No other measurement fell, and with the exception of the sol:serum albumin ratio (see later), comparison between the patients who had received inhaled steroids or placebo indicated no difference in either the time course or the degree of change in the inflammatory parameters (data not shown). The albumin ratio, however, showed a small but significant fall in the steroid treated group, from a

Table 3.-Inflammatory mediators in the stable clinical state

\begin{tabular}{lcc}
\hline & $\begin{array}{c}\text { Mucoid } \\
\text { bronchitics }\end{array}$ & $\begin{array}{c}\text { Purulent } \\
\text { bronchitics }\end{array}$ \\
\hline Samples n & 24 & 33 \\
MPO units $\mathrm{mL}^{-1}$ & $0.42(0.24-0.82)$ & $0.28(0.13-0.40)^{+}$ \\
NE nM & $0.0(0.0-0.0)$ & $0.0(0.0-8.4)$ \\
IL-8 nM & $1.6(0.9-4.1)$ & $4.5(1.9-8.0)^{+}$ \\
LTB $_{4} \mathrm{nM}$ & $3.6(1.2-8.0)$ & $4.7(2.0-6.1)$ \\
Albumin ratio \% & $0.5(0.3-0.8)$ & $0.5(0.3-1.2)$ \\
\hline
\end{tabular}

Data are presented as median (interquartile range). In the stable state there were significant differences in myeloperoxidase (MPO) and interleukin-8 (IL-8) between the two groups of patients. One of the 69 patients was no longer expectorating in the stable clinical state, one had withdrawn from follow-up after developing a pneumothorax, and 10 further sputum samples provided insufficient volume for biochemical analysis after centrifugation. The clinical characteristics of these 12 patients were no different from the patient groups as a whole. $\mathrm{LTB}_{4}$ : leukotriene $\mathrm{B}_{4}$; NE: neutrophil elastase; ${ }^{+}: 2 \mathrm{p}<0.02$. 
median value of $0.43 \%$ (interquartile range; $0.29-$ $0.81)$ at the start of exacerbation, to $0.37 \%(0.23-$ $0.59)$ by the end of the treatment period $(p<0.05)$. The ratio was unchanged in the patients who received the placebo $(0.41 \% ; 0.23-1.42$ versus $0.47 \% ; 0.26-$ 0.59 , respectively).

The time course of the changes in biochemical parameters is summarized for the purulent bronchitics in figures 1-3. A significant reduction in all measures was seen by the fifth day of therapy and except for IL-8 (which rose again after therapy), this was maintained in the stable clinical state. There were no differences in either the time course or the degree of change between the patients who had received 5 or 10 days of antibiotic therapy (data not shown).

\section{$C$-reactive protein}

Figure 4 summarizes the data for both bronchitic groups. At presentation, the CRP values were significantly higher $(\mathrm{p}<0.001)$ in the purulent bronchitics
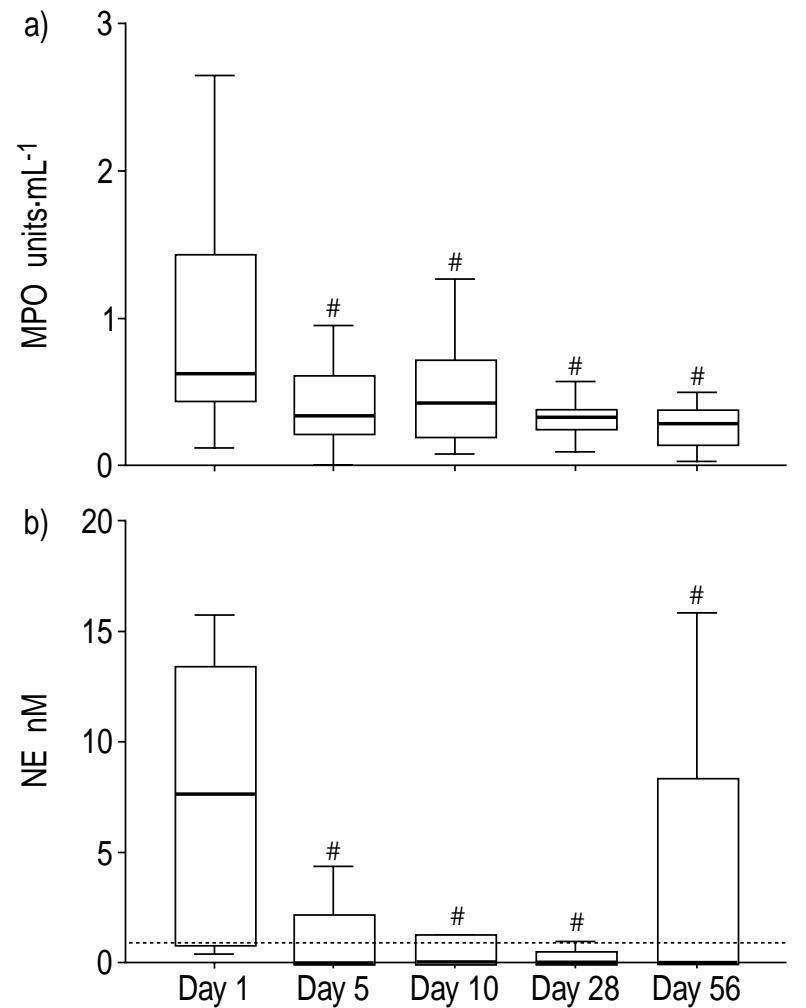

Fig. 1. - Changes in a) myeloperoxidase (MPO) and b) neutrophil elastase (NE) following commencement of treatment for a purulent exacerbation of chronic obstructive pulmonary disease. The horizontal line is the median value, the box is the interquartile range and the whiskers indicate the range, excluding outlying and extreme values (i.e. points with values $\geqslant 1.5$ box lengths from the upper or lower limits of the box). Although all patients were able to provide sufficient sputum for analysis at presentation, it was not possible to obtain adequate samples from every patient at each visit during the subsequent follow-up period (no sputum available or inadequate volume for ultracentrifugation). The number of samples obtained at days $1,5,10,28$ and 56 were $\mathrm{n}=41, \mathrm{n}=36$, $\mathrm{n}=34, \mathrm{n}=25$ and $\mathrm{n}=33$ for fig. a, respectively; and $\mathrm{n}=42, \mathrm{n}=36$, $\mathrm{n}=33, \mathrm{n}=24$ and $\mathrm{n}=32$ for fig. $\mathrm{b}$, respectively. $\#$ : $\mathrm{p}<0.005$, significant differences compared to day 1. - - : the lower limit of detection of the elastase assay.
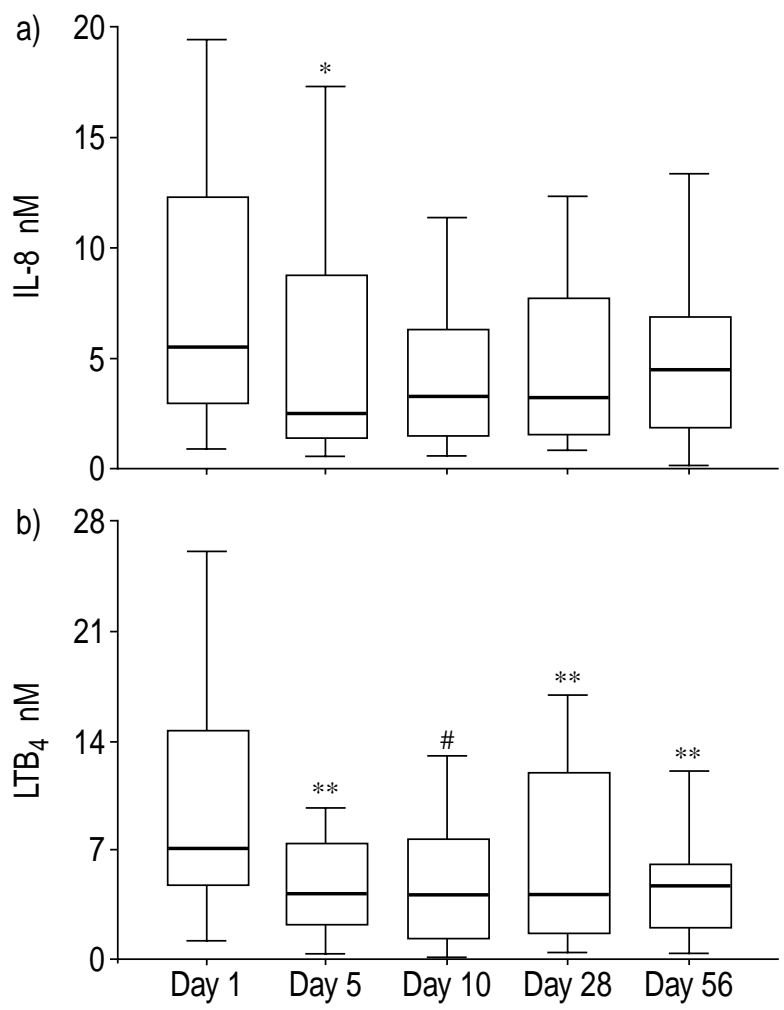

Fig. 2. - Changes in a) interleukin-8 (IL-8) and b) leukotriene $B_{4}$ $\left(\mathrm{LTB}_{4}\right)$ following commencement of treatment for a purulent exacerbation of chronic bronchitis. The horizontal line is the median value, the box is the interquartile range and the whiskers indicate the range, excluding outlying and extreme values (i.e. points with values $\geqslant 1.5$ box lengths from the upper or lower limits of the box). The number of samples obtained at days $1,5,10,28$ and 56 were $\mathrm{n}=41, \mathrm{n}=36, \mathrm{n}=33, \mathrm{n}=24$ and $\mathrm{n}=33$ for fig. a, respectively; and $n=42, n=36, n=34, n=24$ and $n=33$, for fig. b, respectively. ${ }^{*}: \mathrm{p}<0.05$; ${ }^{*}: \mathrm{p}<0.01{ }^{*}: \mathrm{p}<0.005$; significant differences compared to day 1 .

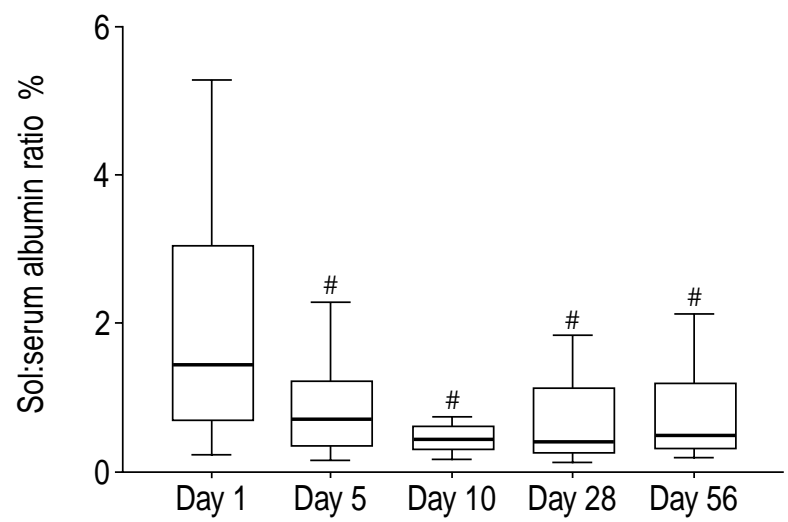

Fig. 3. - Changes in albumin ratio following commencement of treatment for a purulent exacerbation of chronic bronchitis. The horizontal line is the median value, the box is the interquartile range and the whiskers indicate the range, excluding outlying and extreme values (i.e. points with values $\geqslant 1.5$ box lengths from the upper or lower limits of the box). The number of samples obtained at days $1,5,10,28$ and 56 were $n=42, n=34, n=31, n=22$ and $\mathrm{n}=32$, respectively. ${ }^{\#}: \mathrm{p}<0.005$. 


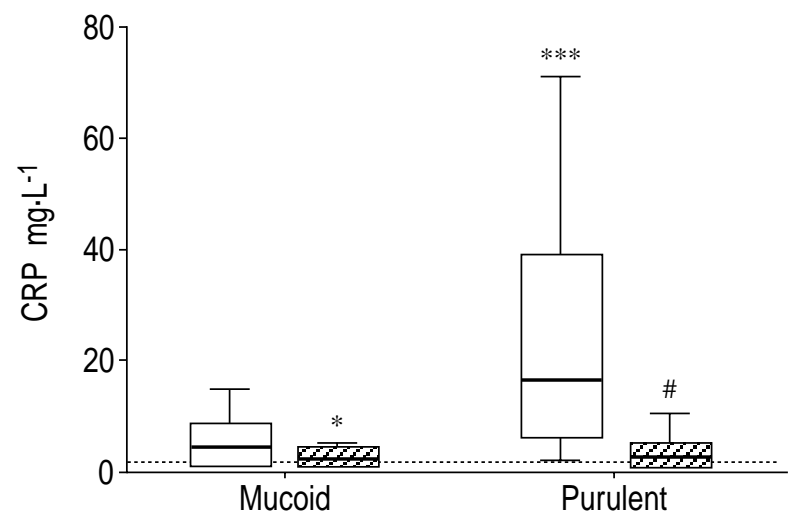

Fig. 4. - C-reactive protein (CRP) in bronchitic patients at presentation (day $1, \square$ ) and in the stable clinical state (day $56, \mathbb{Z})$. The horizontal line is the median value, the box is the interquartile range and the whiskers indicate the range, excluding outlying and extreme values (i.e. points with values $\geqslant 1.5$ box lengths from the upper and lower limits of the box). The number of samples obtained at days 1 and 56 were $n=26$ and $n=25$ for mucoid bronchitis, respectively; and $n=38$ and $n=34$ for purulent bronchitis, respectively. - - : : the lower limit of detection of the assay. *: $\mathrm{p}<0.05 ;{ }^{\#}: \mathrm{p}<0.005$, significance of changes within each group. $* * *: \mathrm{p}<0.001$, significance of the difference between the groups at presentation.

(median $16.7 \mathrm{mg} \cdot \mathrm{L}^{-1}$; interquartile range $6.2-40.3$ ) than in the mucoid bronchitics $\left(4.6 \mathrm{mg} \cdot \mathrm{L}^{-1} ; 1.0-9.1\right)$. By day 56, the CRP had fallen significantly in both groups of patients to $2.7 \mathrm{mg} \cdot \mathrm{L}^{-1}(1.0-5.6 ; \mathrm{p}<0.005)$, and $2.3(1.0-4.9 ; \mathrm{p}<0.05)$ respectively, and they were no longer different.

\section{Discussion}

This study was designed to assess inflammatory changes during the resolution of exacerbations of smoking-related chronic bronchitis, differentiated by sputum purulence at presentation. Patients with mucoid sputum had little evidence of significant bronchial or systemic inflammation, and their sputum bacteriology was similar to that obtained in the stable state. These features are consistent with the a priori decision that antibiotic therapy was not necessary for those patients who presented with mucoid sputum.

There was a minor reduction in sputum MPO activity in the mucoid group as a whole as the episode resolved, but this had returned to the exacerbation level when the subjects were seen in the stable clinical state. This change was not related to steroid therapy or to a relapse in symptoms and the implications remain unknown. Protein leakage also decreased during the first 14 days in this group, but this was confined to the patients who received inhaled steroids. This change is consistent with an anti-inflammatory effect of steroids, and is similar to the effect seen following oral corticosteroid therapy in the stable clinical state [19]. However, other work has shown a significant reduction in sputum chemotactic activity as well as an increase in elastase inhibitory capacity in response to inhaled corticosteroids in the stable state, but not an effect on sol:serum albumin [11]. The present findings suggest that inhaled corticosteroids reduce leakage of serum proteins into the airway during mucoid exacerbations. Although the implications of this are uncertain, the result would be consistent with a clinical benefit of inhaled steroids on severity of exacerbations [12] and oral steroids on more severe exacerbations of COPD necessitating either hospital attendance [20] or hospital admission [21-22], if increased protein leakage were a feature of these episodes. Clearly, further studies are indicated to determine this possibility.

Purulent exacerbations were associated with significant bronchial and systemic inflammation at presentation, and with positive sputum cultures in $90 \%$ of cases. The biochemical resolution of these exacerbations was rapid with results after 5 days being similar to those seen in the stable clinical state. There was no apparent difference in either the speed or magnitude of resolution of inflammation (data not shown) between patients receiving 5 or 10 days of antibiotic. Whether these changes would have occurred without antibiotics is unknown since it was thought unethical to withhold antimicrobial therapy from patients with a change in sputum purulence at presentation.

In the stable clinical state, the reductions in neutrophil influx and activation (MPO and neutrophil elastase), bronchial and systemic inflammation (albumin ratio and $\mathrm{CRP}$, respectively), and in the concentrations of $\mathrm{LTB}_{4}$ were maintained. This was associated with a marked reduction in positive bacterial isolates, indicating that the purulent exacerbations were probably related to new bacterial infection. There were, however, no significant changes in IL-8, suggesting that $\mathrm{LTB}_{4}$ plays a more important role in airway inflammation in the patients with relatively mild exacerbations, treated in the community.

Similar results were presented in a recent prospective study of outpatients with COPD, where there was no change in the concentration of IL- 8 in induced sputum at presentation with an exacerbation [23]. Although these exacerbations described by BHowMIK et al. [2] fulfilled Anthonisen's criteria, sputum purulence was not an inclusion criterion, which may explain why there were no changes in sputum neutrophils, and strict comparison with the presented data is not possible. However, acute, purulent, bacterial exacerbations requiring admission to hospital are associated with more intense inflammation and greater concentrations of chemoattractants $(\sim 10-$ fold higher) than in the present study [24], with marked elevations in IL-8 and $\mathrm{LTB}_{4}$. These results, together with those presented here, would support a hierarchical contribution of chemoattractants [25], with $\mathrm{LTB}_{4}$ being the first to change at low levels of neutrophil influx (mild purulent exacerbations), and IL-8 becoming increasingly involved as neutrophil influx and activation becomes more intense (in more severe, purulent exacerbations).

The concentration of IL- 8 in the stable state was higher in patients who had presented with purulent sputum. Airway levels of this cytokine are related to airflow obstruction [26], smoking status [27] and bacterial colonization $[28,29]$. The purulent bronchitics were more obstructed, on average, than the 
mucoid patients (although this just failed to achieve a conventional level of statistical significance). This could explain the difference in IL- 8 between the two groups, since they were otherwise matched for bacterial colonization in the stable state and for smoking status. A final possibility is that these patients represent a group prone to frequent exacerbations, supporting the findings of BHOWMIK et al. [23]. Further studies are necessary to resolve this possibility.

In the present study, biochemical analyses have been performed on sputum samples from a large number of patients who were followed prospectively from the onset of an acute exacerbation of chronic bronchitis to its resolution. The presented data provide clear evidence of two types of exacerbation, which could be differentiated by sputum colour at presentation. Mucoid exacerbations appeared to be unrelated to bacterial infection and were not associated with neutrophilic inflammation. Purulent exacerbations were associated with significant bronchial and systemic inflammation and positive bacterial cultures, suggesting that they were related to bacterial infection; leukotriene $\mathrm{B}_{4}$ appeared to be an important chemoattractant in these patients.

Acknowledgements. The authors acknowledge the central role of three respiratory research nurses, B. Leung, K. Verbeet and M. Henson, in patient recruitment and encouragement.

\section{References}

1. American Thoracic Society. Standards for the diagnosis and care of patients with chronic obstructive pulmonary disease. Am J Respir Crit Care Med 1995; 152: S77-S120.

2. Anthonisen NR, Manfreda J, Warren CPW, Hershfield ES, Harding GKM, Nelson NA. Antibiotic therapy in exacerbations of chronic obstructive pulmonary disease. Ann Intern Med 1987; 106: 196-204.

3. Balbi B, Bason C, Balleari E, et al. Increased bronchoalveolar granulocytes and granulocyte/macrophage colony-stimulating factor during exacerbations of chronic bronchitis. Eur Respir J 1997; 10: 846-850.

4. Maestrelli P, Saetta M, Di Stefano A, et al. Comparison of leukocyte counts in sputum, bronchial biopsies and bronchoalveolar lavage. Am J Respir Crit Care Med 1995; 152: 1926-1931.

5. Saetta M, Di Stefano A, Maestrelli P, et al. Airway eosinophilia in chronic bronchitis during exacerbations. Am J Respir Crit Care Med 1994; 150: 1646-1652.

6. Stockley RA, Burnett D. Alphal-antitrypsin and leukocyte elastase in infected and non-infected sputum. Am Rev Respir Dis 1979; 120: 1081-1086.

7. Sachs APE, Koëter GH, Groenier KH, van der Waajj $\mathrm{D}$, Schiphuis J, Meyboom-de-Jong B. Changes in symptoms, peak expiratory flow rate, and sputum flora during treatment with antibiotics of exacerbations in patients with chronic obstructive pulmonary disease in general practice. Thorax 1995; 50: 758-763.

8. O'Brien C, Guest PJ, Hill SL, Stockley RA. Physiological and radiological characterisation of patients diagnosed with chronic obstructive pulmonary disease in primary care. Thorax 2000; 55: 635-642.

9. Saetta M, Di Stefano A, Maestrelli P, et al. Airway eosinophilia and expression of interleukin-5 protein in asthma and in exacerbations of chronic bronchitis. Clin Exp Allergy 1996; 26: 766-774.

10. Pye A, Stockley RA, Hill SL. Simple method for quantifying viable bacterial numbers in sputum. $J$ Clin Pathol 1995; 48: 719-724.

11. Llewellyn-Jones CG, Harris TAJ, Stockley RA. Effect of fluticasone propionate on sputum of patients with chronic bronchitis and emphysema. Am J Respir Crit Care Med 1996; 153: 616-621.

12. Paggiaro PL, Dahle R, Bakrani I, Frith L, Hollingworth $\mathrm{K}$, Efthmiou J. Multicentre randomised placebocontrolled trial of inhaled fluticasone propionate in patients with chronic obstructive pulmonary disease. Lancet 1998; 351: 773-780.

13. Murphy TF, Sethi S. Bacterial infection in chronic obstructive pulmonary disease. Am Rev Respir Dis 1992; 146: $1067-1083$.

14. Naidich DP, McCauley DI, Khouri NF, Stitik FP, Siegelman SS. Computed tomography of bronchiectasis. J Comput Assist Tomogr 1982; 6: 437-444.

15. Hansell DM. Bronchiectasis. In: Webb WR, ed. Imaging in obstructive pulmonary disease. Philadelphia, WB Saunders Company, 1998; pp. 107-128.

16. Gompertz S, O'Brien C, Bayley D, Leung B, Hill SL, Stockley RA. Comparison of stable state bronchial inflammation in chronic bronchitis and previously unsuspected bronchiectasis (BE). Eur Respir J 1999; 14: Suppl. 30, 165S.

17. Stockley RA, Bayley D. Validation of assays for lung inflammatory markers. Eur Respir J 2000; 15: $778-$ 781.

18. Stockley RA, Hill SL, Morrison HM, Starkie CM. Elastolytic activity of sputum and its relation to purulence and to lung function in patients with bronchiectasis. Thorax 1984; 39: 408-413.

19. Wiggins J, Elliot JA, Stevenson RD, Stockley RA. Effect of corticosteroids on sputum sol-phase protease inhibitors in chronic obstructive pulmonary disease. Thorax 1982; 37: 652-656.

20. Thompson WH, Nielson CP, Carvalho P, Charan NB, Crowley JJ. Controlled trial of oral prednisone in outpatients with acute COPD exacerbation. Am J Respir Crit Care Med 1996; 154: 407-412.

21. Davies L, Angus RM, Calverley PMA. Oral corticosteroids in patients admitted to hospital with exacerbations of chronic obstructive pulmonary disease: a prospective randomised controlled trial. Lancet 1999; 354: $456-460$

22. Niewoehner DE, Erbland ML, Deupree RH, et al. Effect of systemic glucocorticoids on exacerbations of chronic obstructive pulmonary disease. $N$ Engl J Med 1999; 340: 1941 - 1947.

23. Bhowmik A, Seemungal TAR, Sapsford RJ, Wedzicha JA. Relationship of sputum inflammatory changes to symptoms and lung function changes in COPD exacerbations. Thorax 2000; 55: 114-120.

24. Crooks S, Bayley DL, Hill SL, Stockley RA. Bronchial inflammation in acute bacterial exacerbations of chronic bronchitis: the role of leukotriene $\mathrm{B}_{4}$. Eur Respir J 2000; 15: 274-280.

25. Hill AT, Bayley DL, Stockley RA. The interrelationship of sputum inflammatory markers in patients with 
chronic bronchitis. Am J Respir Crit Care Med 1999; 160: 893-898.

26. Yamamoto C, Yoneda T, Yoshikawa M, et al. Airway inflammation in COPD assessed by sputum levels of interleukin-8. Chest 1997; 112: 505-510.

27. Hill AT, Bayley DL, Campbell EJ, Hill SL, Stockley RA. Airways inflammation in chronic bronchitis: the effects of smoking and $\alpha-1$-antitrypsin deficiency. Eur Respir J 2000; 15: 886-890.
28. Soler N, Ewig S, Torres A, Filella X, Gonzalez J, Zaubert A. Airway inflammation and bronchial patterns in patients with stable chronic obstructive pulmonary disease. Eur Respir J 1999; 14: 1015-1022.

29. Hill AT, Campbell EJ, Hill SL, Crooks S, Bayley DL, Stockley RA. Association between airway bacterial load and markers of airway inflammation in patients with stable chronic bronchitis. Am J Med 2000; 109: $288-295$. 